\title{
CNS-Immune Reconstitution Inflammatory Syndrome in the Setting of HIV Infection, Part 1: Overview and Discussion of Progressive Multifocal Leukoencephalopathy-Immune Reconstitution Inflammatory Syndrome and Cryptococcal- Immune Reconstitution Inflammatory Syndrome
}

\author{
M.J.D. Post, M.M. Thurnher, D.B. Clifford, A. Nath, R.G. Gonzalez, R.K. Gupta, and K.K. Post
}

\begin{abstract}
SUMMARY: While uncommon, CNS-IRIS developing after the initiation of HAART in the setting of HIV-related severe immunosuppression is characterized by an intense inflammatory reaction to dead or latent organisms or to self-antigens due to a heightened but dysregulated immune response. While this reaction can range from mild to fulminating, encompassing a very wide clinical spectrum, it is important to recognize because changes in medical management may be necessary to prevent neurologic decline and even death. Once contained, however, this inflammatory response can be associated with improved patient outcome as immune function is restored. Among the infectious organisms that are most commonly associated with CNS-IRIS are the JC virus and Cryptococcus organisms, which will be the subject of this review. CD8 cell infiltration in the leptomeninges, perivascular spaces, blood vessels, and even parenchyma seems to be the pathologic hallmark of CNS-IRIS. While recognition of CNS-IRIS may be difficult, the onset of new or progressive clinical symptoms, despite medical therapy and despite improved laboratory data, and the appearance on neuroimaging studies of contrast enhancement, interstitial edema, mass effect, and restricted diffusion in infections not typically characterized by these findings in the untreated HIV-infected patient should raise the strong suspicion for CNS-IRIS. While CNS-IRIS is a diagnosis of exclusion, the neuroradiologist can play a critical role in alerting the clinician to the possibility of this syndrome.
\end{abstract}

ABBREVIATIONS: ART = antiretroviral therapy; $C M=$ cryptococcal meningitis; HAART = highly active antiretroviral therapy; IRIS = immune reconstitution inflammatory syndrome; JCV = JC virus; $\mathrm{OI}=$ opportunistic infection; PML = progressive multifocal leukoencephalopathy; Th = T-helper cell

RIS, first described in 1992, occurs most commonly in the setting of HIV immunosuppression, ${ }^{1}$ the focus of this article. When IRIS occurs in HIV-infected individuals, it develops within weeks, months, or, rarely, years after the initiation of HAART and represents an exuberant inflammatory response to an antigen that is either to a dead or dying organism resulting from an OI or a viable pathogen from a persistent infection, or to self-antigens. ${ }^{1-46}$ This exaggerated inflammatory response can be recognized by the development of new clinical symptoms or worsening

From the Section of Neuroradiology (M.J.D.P.), Department of Radiology, University of Miami Miller School of Medicine, Jackson Memorial Medical Center, Miami, Florida; Department of Radiology (M.M.T.), University of Vienna, University Hospital Vienna, Vienna, Austria; Department of Neurology (D.B.C.), Washington University in St. Louis, St. Louis, Missouri; Section of Infections of the Nervous System (A.N.), National Institute of Neurological Disorders and Stroke, National Institutes of Health, Bethesda, Maryland; Department of Radiology (R.G.G.), Harvard Medical School and Massachusetts General Hospital, Boston, Massachusetts; Department of Radiology (R.K.G.), Sanjay Gandhi Postgraduate Institute of Medical Sciences, Lucknow, India; and Department of Internal Medicine (K.K.P.), UMass Memorial Medical Center-University Campus, Worcester, Massachusetts.

Please address correspondence to M. Judith Donovan Post, MD, Section of Neuroradiology, Department of Radiology, University of Miami Miller School of Medicine, Jackson Memorial Medical Center, West Wing 279, 1611 NW 12th Ave, Miami, FL 33136; e-mail: jpost@med.miami.edu

-- Indicates open access to non-subscribers at www.ajnr.org

http://dx.doi.org/10.3174/ajnr.A3183 of existing clinical symptoms despite adequate treatment of the OI and by specific abnormalities on MR imaging or CT that are usually distinct from the imaging findings that are characteristic of that particular offending OI. ${ }^{1-46}$ While this robust inflammatory response is usually self-limiting and often associated with mild symptoms and eventual immune restoration, it can be fulminating, with death ensuing a short time after symptom onset. ${ }^{1}$ Furthermore, because IRIS has been reported by many investigators to have an overall incidence at least as high as $25 \%-35 \%$, increasing to $45 \%$ in those with underlying OIs, ${ }^{2,9,10,16}$ it significantly negatively impacts the HIV-infected population on HAART by increasing the number of procedures, number of hospitalizations, and the overall morbidity in this patient cohort. ${ }^{2}$

Morbidity and mortality rates are even more exaggerated in developing countries, indicating a global health concern. ${ }^{1}$ It is evident, then, that strategies for promptly recognizing and treating patients with IRIS are critical to the ongoing fight against HIV infection in the post-HAART era so that further strides in improving quality of life can be ensured. Also critical is the realization that IRIS might be averted if steps are taken to prevent CD4 counts from dropping below 50 cells per microliter and OI is prevented. ${ }^{5}$

In those HIV-infected patients on HAART who do develop 
IRIS when their T-cell antigen-specific immunity is reconstituted following an anergic state, ${ }^{8}$ the risk factors for the development of IRIS include the following: 1) the patient being HAART-naïve, which allows a more intense inflammatory response to devel$\left.\mathrm{op}^{2,7,8} ; 2\right)$ the patient being severely immunocompromised with very low $\mathrm{CD} 4$ counts $(<50$ cells per cubic millimeter) at the initiation of $\mathrm{ART}^{5,7,11}$; 3) high pre-HAART HIV-1 RNA levels; 4) falling HIV-1 RNA levels in response to HAART initiation, especially when this fall occurs rapidly and results in significant level reductions and when it takes place within 90 days of the introduction of HAART ${ }^{2,8,12-14}$; 5) rising CD4 counts after initiation of HAART, especially later in the course of therapy after falling HIV-1 RNA levels have resulted in an initial redistribution of memory CD4 lymphocytes ${ }^{2,8}$; 6) OI or the patient on treatment for OI when HAART is initiated, especially within a month of the OI diagnosis, because the increased antigenic burden evokes a more robust inflammatory response $\mathrm{e}^{2,7,16}$; 7) resumption of HAART after an interruption; 8) younger age; 9) male sex; and 10) genetic factors that alter the clearance of the pathogen (such as with herpesviruses or mycobacteria) or enhance the immune response to it via polymorphisms in cytokine genes. ${ }^{8,15}$

While some of these risk factors are still being debated, such as age and sex, ${ }^{8}$ and while criteria are still being expanded and further defined ${ }^{2,17}$ and the pathogenesis of IRIS remains not wellunderstood (with some investigators suggesting that there may even be different mechanisms for different pathogens), 7,18,28 there is general acceptance that IRIS can be diagnosed in an HIVinfected individual when there is evidence that the patient's immune system is reconstituting (higher CD4 counts and decreasing HIV-1 RNA levels), yet the patient is paradoxically worsening with the development of new symptoms that cannot be explained by drug toxicity, OI, medical noncompliance, or allergic reactions. ${ }^{6,16,19}$ IRIS then is often a diagnosis of exclusion. ${ }^{8}$ Diagnosis, however, can be supported by the detection of atypical imaging and laboratory findings, such as new imaging patterns and laboratory tests that might not show viable organisms. Pathologically, T-cell infiltration confirms the diagnosis. ${ }^{1}$ Conversely, a factor that does not seem to alter the development of IRIS includes the specific type of HAART. ${ }^{2}$ For example, patients on protease-containing regimens had a similar risk of the development of IRIS as those HIV-infected individuals on non-protease-containing regimens. $^{2}$

Curiously, then, the HIV-infected patient on HAART shows evidence of reconstituting his or her immune system, yet paradoxically, that patient begins to fare worse than he or she did before the HAART was initiated. ${ }^{2}$ While it is seemingly inexplicable that the patient can worsen despite instituting appropriate HAART, this adverse reaction, known as IRIS, can be explained by the fact the reconstituted immune system is not a reconstituted "normal" immune system-rather it is an exaggerated response. ${ }^{2}$ As a result, the inflammatory reaction to either subclinical infections or infections that have been previously treated is a pathologic one with an intense cellular proliferative response. ${ }^{2,12}$ Consequently, extremely immunosuppressed individuals while on their way to immune reconstitution with HAART develop a pathogen-specific immune response that results in excessive tissue inflammation. ${ }^{12}$ A biphasic immune reconstitution occurs with the first stage characterized by the prompt release of memory T-cells into the circulation and the second stage typified by a gradual rise in naïve T-cell production. ${ }^{1}$ More specifically within the first 2 weeks of HAART, during the first stage of immune restoration, there is a rapid decrease in the HIV viral load. ${ }^{1}$ The circulating CD8 + T-cells also rapidly increase. ${ }^{1}$ Additionally, there is a rise in the number of $\mathrm{CD} 4+\mathrm{T}$-cells due to a redistribution of pre-existing memory $\mathrm{T}$-cells caused by a release into the circulation of these cells from lymphoid tissue. ${ }^{1,19}$ These memory $\mathrm{T}$-cells respond faster to an antigenic stimulus and demonstrate faster effector functions than naïve T-cells, perhaps explaining why a mild OI may result in an exaggerated response. ${ }^{1,19}$

After 1-1.5 months, there is a proliferation of naïve T-cells from the thymus, which can last up to 2 years and constitutes the second stage of immune restoration, which may be responsible for the continuation of IRIS. ${ }^{1,19}$ There is also an alteration or imbalance in the proinflammatory T-helper cells (including the Th1 cells, which help clear intracellular pathogens, and the Th17 cells, which help sustain inflammatory responses by producing certain cytokines) and regulatory T-cells, which suppresses effector $\mathrm{CD} 4+$ and $\mathrm{CD} 8+$ cell proliferation and their cytokine production. $^{8}$

The homeostatic state cannot be maintained, and a robust inflammatory response develops, which is difficult to contain. ${ }^{8}$ Consequently, patients may develop recurrence of the initial symptoms associated with their infection or they may develop new inflammatory symptoms following institution of HAART, such as fever, pain from nodal enlargement, and headache. ${ }^{2}$ Imaging studies in patients with systemic IRIS manifestations may show increasing abnormalities, such as new or worsening lymphadenopathy, enlarging liver, or increasing pulmonary infiltration, all in the face of cultures that are often negative. ${ }^{2}$ Necrotizing lymphadenitis, disseminated infection from Mycobacterium tuberculosis or Mycobacterium avium complex, may be seen $^{2}$ and may give insight into CNS-IRIS.

Concerning IRIS terminology, the robust inflammatory reaction to a persistent antigen has been termed "paradoxical" IRIS or, as suggested by Johnson and Nath, "delayed" IRIS. ${ }^{1}$ In this scenario, the antigen has been previously identified and treated. ${ }^{1,20}$ However, when the intense inflammatory response is a reaction to a viable pathogen related to a latent infection, the term "unmasking" IRIS or "simultaneous" IRIS has been used. ${ }^{2,5,20}$ With respect to the incidence of IRIS, in a cohort of 180 HIV-infected individuals on HAART who were coinfected with Mycobacterium tuberculosis, Mycobacterium avium complex, or Cryptococcus neoformans, IRIS occurred in $31.7 \%$, with a 27 -day median time between treating the OI and the onset of HAART. ${ }^{2}$ While in most patients in this particular cohort, the onset of IRIS occurred within 60 days, ${ }^{2}$ IRIS onset was seen in some patients up to 2 years after the institution of HAART. ${ }^{2}$ Surprisingly, the long-term outcome of those patients who developed IRIS was generally favorable, with immune reconstitution and viral suppression seen typically after 24 months. ${ }^{2}$ An increase in CD4 cell count of $100 \times 10^{6}$ cells/L over baseline and an HIV-1 RNA level of $<400$ copies $/ \mathrm{mL}$ at 24 months was defined in this study as successful immune restoration. ${ }^{2}$ Interestingly enough, while aggressive short-term therapy such as corticosteroid administration was needed in some 
patients to minimize the effects of IRIS, the long-term outcome was typically good. ${ }^{2}$ Nevertheless, the immune dysfunction that causes IRIS can persist in some individuals.

In another investigation that included a systematic review and a meta-analysis, 1699 patients or $12.97 \%$ from 54 cohort studies were reported to have developed IRIS of a total of 13,103 patients started on ART. ${ }^{5}$ Pooled cumulative incidences were then calculated by specific disease processes in patients with previously confirmed AIDS-defining illnesses. ${ }^{5}$ Those IRIS incidences were as follows: $37.7 \%$, cytomegalovirus retinitis; $19.5 \%$, cryptococcal meningitis; 16.7\%, PML; 15.7\%, tuberculosis; $12.2 \%$, herpes zoster; and 6.4\%, Kaposi's sarcoma. ${ }^{5}$ Among unselected patients in whom ART was initiated, IRIS of any type was diagnosed in $16.1 \%$, with $4.5 \%$ of those succumbing to this syndrome. ${ }^{5}$ However, when patients were selected according to disease process, the percentages of those dying changed. ${ }^{5}$ In patients with cryptococcal meningitis-associated IRIS, $20.8 \%$ died in contrast to $3.2 \%$ of patients in whom IRIS was associated with tuberculosis. ${ }^{5}$ From these statistics, it is evident then that the incidence as well as severity of the reaction and the mortality rates of IRIS vary with the specific type of patient population being studied, the type of AIDS-defining illness, and also the geographic locale (global location) in which these patients reside. These differences as well as the paucity of investigations dealing with large patient populations with IRIS and the evolving definitions of IRIS make it difficult to globally standardize and optimize the diagnosis and treatment of patients with IRIS. Nevertheless, investigators are searching for biomarkers for CNS-IRIS such as elevated plasma interleukin 6 levels, certain cytokine profiles, and genetic markers with profiles of gene expression for diagnosing and monitoring IRIS. ${ }^{1}$

While IRIS can affect any organ in the body, such as the lungs, liver, and lymph nodes, it uncommonly targets the CNS, ${ }^{7}$ where it has an incidence ranging from only 0.9 to $1.5 \% .^{1,21}$ Nevertheless, when CNS-IRIS develops, it can have a serious impact on patient morbidity and mortality. Mortality rates can range from $5 \%$ up to $15 \% .^{15,21,22}$ At autopsy or at brain biopsy, the typical pathology in CNS-IRIS has been characterized by a CD8 + T-cell lymphocytosis with CD8 + cells found in a perivascular and even in a parenchymal location, ${ }^{16,23,24}$ leading to encephalitis. The relative paucity of CD4 + cells in the brain despite a rising peripheral CD4 cell count in patients on HAART has led Gray et $\mathrm{al}^{23}$ to postulate that the underlying etiology responsible for IRIS is a dysregulated CD8+/CD4+ lymphocyte ratio. In the 8 fatal cases reported by Gray et al, ${ }^{23} \mathrm{CD} 4$ cells, while increasing in the periphery, did not cross the blood-brain barrier, explaining the absence of CD4+ cells in the brain in most cases. ${ }^{16}$

While recognition of CNS-IRIS both from a clinical and imaging standpoint can be quite difficult because of all its diverse presentations and because it results from a pathogen-specific antigenic response, it is essential to recognize this syndrome so that appropriate therapy can be initiated. Therefore, this review will mainly focus on HIV-associated CNS-IRIS and how to recognize the various expressions of CNS-IRIS, focusing especially on imaging characteristics in PML-IRIS and in cryptococcal meningitis-IRIS.

\section{COMMON PATHOGENS ASSOCIATED WITH CNS-IRIS}

Virus: PML-IRIS in HIV + Patients on HAART. It has been reported that in $18 \%$ of HIV + patients with PML, an opportunistic infection caused by the human JC virus, a polyoma virus, PMLIRIS may develop in those treated with HAART. ${ }^{15,47}$ Depending on the method of diagnosis, however, this figure may be $50 \%$ or higher (personal communication, D. Clifford, January 24, 2012). These figures are notable because while some PML-IRIS cases are mild and resolve with continued HAART, other cases may lead to significant morbidity and even mortality because of a severe inflammatory response characterized histopathologically by a marked influx of CD8 + T-cell lymphocytes and macrophages in the areas of demyelination and inflammatory reaction. . $^{6,15,37,48-61}$ In fact, in 2 cases, PML-IRIS proved fatal after only 2 weeks of HAART. ${ }^{6}$ Presumably, the vast outnumbering of CD8 + T-cell lymphocytes compared with CD4 + T-cell lymphocytes may produce an uncontrolled inflammatory response that could prove fatal. ${ }^{6}$ Because JCV-specific CD4+ T-cell lymphocytes are also known to play a role in the containment of PML, their paucity and the markedly altered $\mathrm{CD} 8+/ \mathrm{CD} 4+$ ratio are also contributory factors. ${ }^{6}$ The use of early and prolonged steroids has been suggested as a means of combating this exaggerated inflammatory response to either the detectable or latent JC virus infection. ${ }^{15}$

In contrast to PML-IRIS, PML untreated by HAART, when caused by reactivation of the latent and ubiquitous JC virus due to the synergistic effect of HIV ${ }^{47,63,64}$ typically results in demyelination, necrosis, and cell death because of a noninflammatory lytic reaction arising from the infection by the virus of the oligodendrocytes and astrocytes. ${ }^{15}$ It is the T-cell immune deficit caused by HIV that is hypothesized to allow rearrangement of the regulatory region in JCV DNA, which leads to the virus becoming neurotropic and gaining entry to the brain. ${ }^{15}$ The virus, which is released from the bone marrow or lymphoid tissue stores, is thought to travel hematogeneously to the brain, most probably in B-cells or their precursors. ${ }^{15}$ Unfortunately, to date, no effective therapy that directly targets the JC virus has been developed.

With the institution of HAART, however, the prognosis for HIV-associated PML has been shown to improve, as in a study of 25 such patients in whom the median survival time was $>46$ weeks compared with a 10.6-week median survival time in an AIDS Clinical Trials Group study of PML in HIV + patients before the advent of HAART. ${ }^{65}$ Increased survival times also correlated with reductions in HIV RNA viral loads. ${ }^{65}$ Gasnault et al ${ }^{66}$ also found, in a study of 81 patients with AIDS and PML, a significant survival benefit in those treated with combined antiretroviral therapy. In a different investigation, a median duration of 2.2 years on HAART was found in $63.6 \%$ of HIV + patients with PML, with half of those showing neurologic improvement. ${ }^{64,67}$ This increased patient survival has been directly linked, in a report by Katz-Brull et al, ${ }^{68}$ to the degree of inflammatory response mounted by the patient. Katz-Brull et al ${ }^{68}$ postulated that because disease progression in PML could be mitigated by the inflammatory reaction induced by $\mathrm{CD} 8+$ cytotoxic $\mathrm{T}$ lymphocytes specific for the JC virus, they could use myo-inositol, a glial marker, as measured by proton MR spectroscopy, as a surrogate marker for brain inflammation and, therefore, as a prognostic tool. Those patients with PML with higher ratios of myo-inositol-to-creatine 


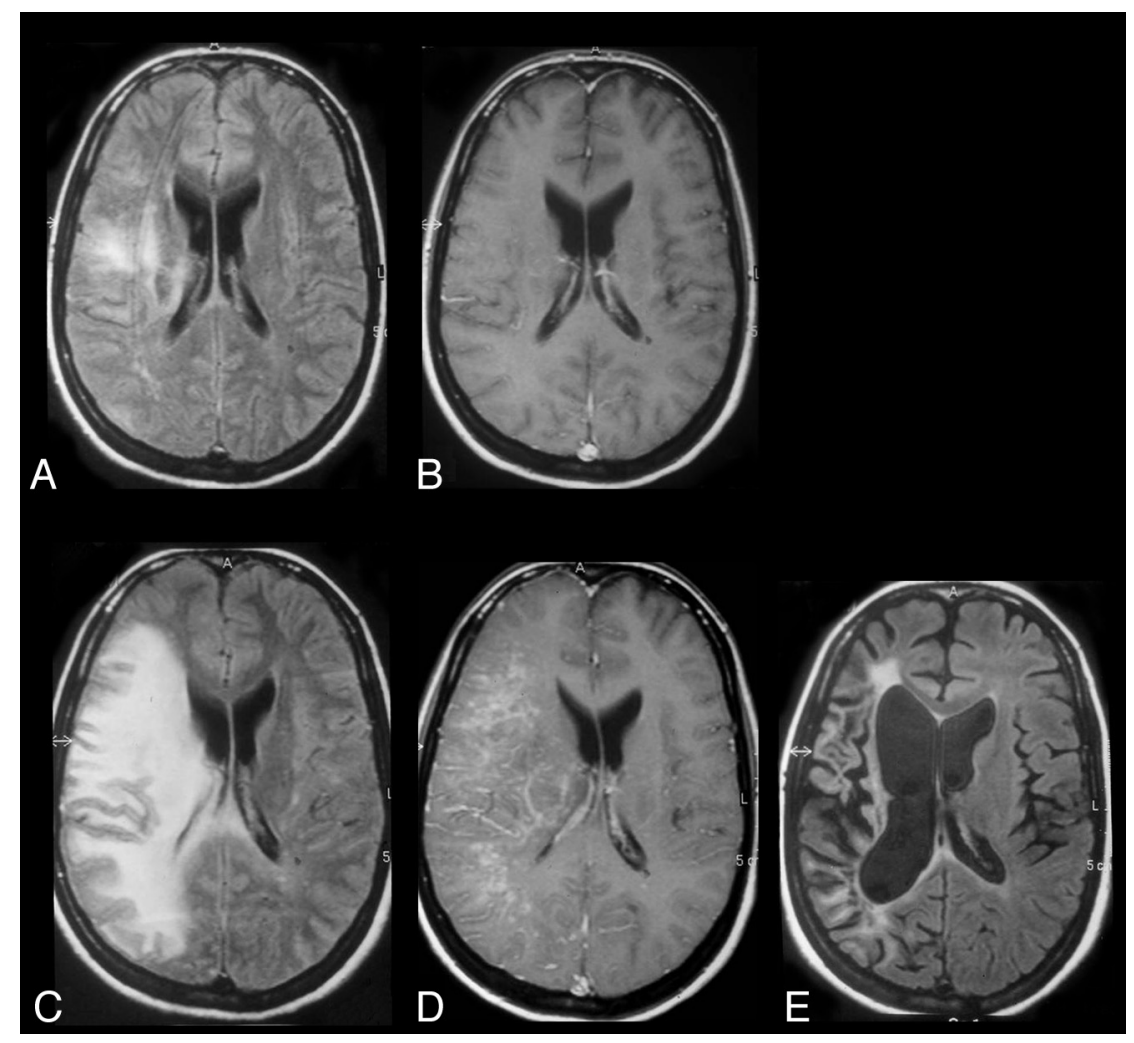

FIG 1. PML-IRIS. Patient with AIDS and PML whose initial MR imaging on axial FLAIR $(A)$ and contrast TIWI (B) shows subcortical and deep white matter lesions due to PML, evidenced by high FLAIR signal without any enhancement. One month later, after HAART initiation, a marked increase in FLAIR high signal (C) compatible with interstitial edema, mass effect, and on contrast TTWI parenchymal and perivascular enhancement (D) develops compatible with PML-IRIS. Long-term follow-up MR imaging with axial FLAIR (E) shows resolution of most of the high-signal abnormalities and atrophy with cortical sulcal and ventricular dilation and no enhancement (not shown). Figures were reproduced with permission from Thurnher et al. ${ }^{71}$

levels as well as the presence of JC virus-specific cytotoxic T lymphocytes in the blood appeared to have their PML progression limited by this inflammatory reaction, resulting in increased patient survival. ${ }^{68}$ The cytokines produced by the CD8 + T-cell lymphocytes were postulated as causing this elevation in myo-inositol by inducing an increase in glial cell size and content, leading to a more robust inflammatory response. ${ }^{68}$

Other authors have found proton MR spectroscopy useful as well. ${ }^{69,70}$ For example, a study by Chang et $\mathrm{al}^{70}$ of $\mathrm{HIV}+$ patients with PML on HAART found that those patients with higher myoinositol levels on proton MR spectroscopy had higher survival rates. Yet another positive predictor value for increased survival in those with PML on HAART was found by Berger et $\mathrm{al}^{58}$ to be the presence of lesional contrast enhancement on MR imaging. These imaging findings predictive of improved patient outcome were also found in an MR imaging study by Thurnher et $\mathrm{al}^{71}$ of the initial and follow-up MR imaging findings in AIDS-related PML treated with HAART. This investigation demonstrated that a transient increase in high FLAIR signal and contrast enhancement in the white matter and subsequent MR imaging findings of leukomalacia and atrophy correlated with increased survival (Fig 1). ${ }^{71}$ Yet another measurable benefit for patients with PML on HAART was found by Usiskin et al, ${ }^{72}$ who demonstrated white matter anisotropy restoration with treatment. ${ }^{72,73}$ Unfortunately, however, despite the fact that $10 \%-50 \%$ of patients with PML have their 1-year survival rate increased by HAART, 50\% of those patients still die. ${ }^{74}$ Furthermore, patients with AIDS being treated with HAART may subsequently develop PML. ${ }^{6}$

As for the considerable number of patients on HAART who develop PML-IRIS, the robust inflammatory response that typifies PML-IRIS may be seen any time between 1 week and 26 months after HAART initiation, but most commonly at 3 months, ${ }^{15,73}$ perhaps due to the restoration of T-cell function peaking at this time. ${ }^{6}$ This wide time range in which PML-IRIS may develop has been postulated to be related to the initial redistribution in the first several weeks of pre-existing memory T-cells followed 1 month to 4 years later by the proliferation of naïve T-cells. ${ }^{73}$ In trying to determine what factors can be used to indicate a better prognosis in those patients with known PML-IRIS, a recent investigation of the cellular immune response to the JC virus measuring both $\mathrm{CD} 4+$ and $\mathrm{CD} 8+\mathrm{T}$-cells via proliferation assays to the JCV antigen and via JCV peptide stimulation showed that the JC-specific CD8 + T-cell response was significantly lower in the PML-IRIS progressors versus the PML-IRIS survivors as was the detectable CD4+ T-cell response. ${ }^{75}$ Because it is the JC virus-specific cytotoxic CD8 + T lymphocytes that induce an avid cellular immune response, it is these lymphocytes that help contain PML. ${ }^{6}$

In another study, one consisting of 54 patients with PML-IRIS, the patients who fared worse, having shortened survival rates (2.5 weeks versus 8.5 weeks) and increased mortality, were those whose pre-existing PML worsened after HAART initiation, who 


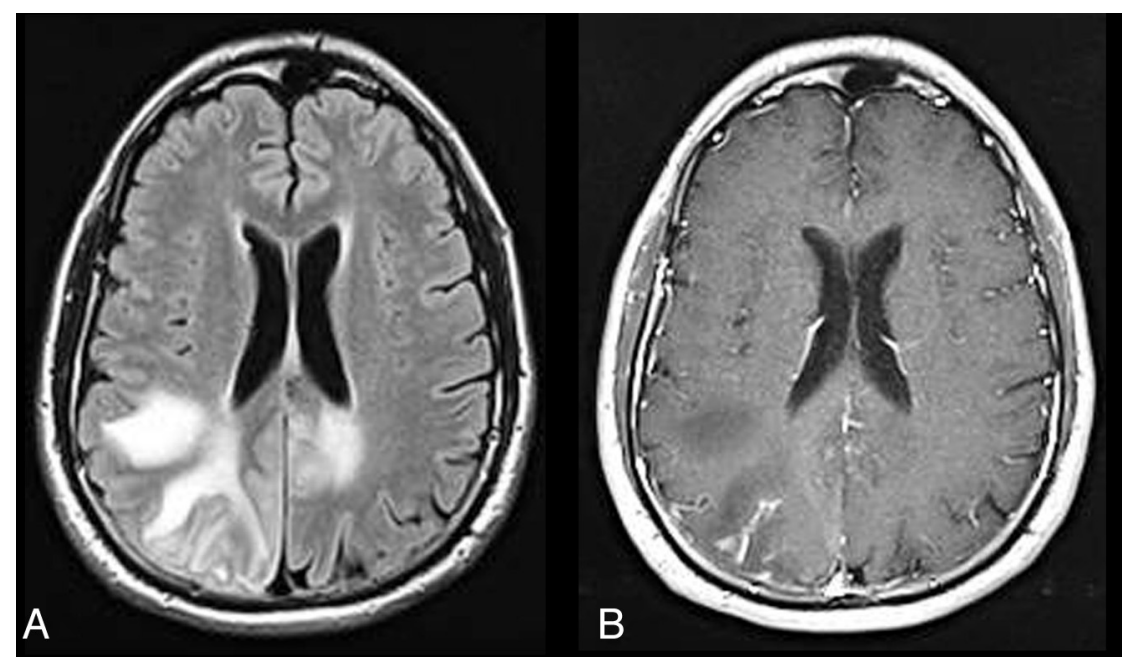

FIG 2. PML-IRIS. HIV-infected patient on HAART with axial FLAIR $(A)$ showing multiple hyperintense asymmetric lesions in the white matter bilaterally and axial postcontrast TIWI (B) showing some patchy enhancement in the right parietal region due to PML-IRIS. Significant response to corticosteroid therapy confirms IRIS.

developed IRIS earlier on, and who had higher MR imaging lesion loads, compared with those patients who developed IRIS simultaneously with PML. ${ }^{15}$ Increased survival in this same report was associated with earlier and more prolonged use of steroids as well as contrast enhancement on imaging studies ${ }^{15} ; 87.5 \%$ of those patients with a good outcome demonstrated lesional contrast enhancement on either CT or MR imaging versus $80 \%$ with poor outcome whose imaging demonstrated no contrast enhancement. ${ }^{15}$ In 2 other studies, this perilesional contrast enhancement and its intensity were found to be correlated with the sites and severity of brain inflammation at brain biopsy. ${ }^{15,76,77}$ It appears then that some degree of inflammatory response following HAART is a good thing, whether associated with the IRIS phenomenon or not. However, if the inflammatory response becomes excessive and uncontrollable, morbidity and mortality rates increase, unless mitigated by medical therapy such as steroids, because it is likely that much of the current mortality of PML is linked to IRIS rather than to progressive JC virus-driven disease.

What now makes PML-IRIS more recognizable than IRIS associated with some other opportunistic diseases, in addition to atypical clinical findings, is the presence of neuroimaging abnormalities that are not classic for untreated PML. While untreated PML typically presents as white matter lesions, often subcortical, low on T1WI, and high on FLAIR and T2WI (due to the myelin destruction), without mass effect and without contrast enhancement with no diffusion restriction centrally (but only peripherally at the active site of lesion expansion with cytotoxic edema), ${ }^{62,78}$ PML-IRIS is characterized by the development of contrast enhancement of the PML lesions as well as mass effect and increased high FLAIR/T2 signal due to interstitial edema (Figs 2-4). ${ }^{15,58,71,73,76-80}$ Usually occurring within 1-2 months of HAART $^{1,30}$ (though they can occur up to 2 years), patchy white matter lesions with multiple areas of nodular enhancement on MR imaging can be seen, which can respond to steroids. ${ }^{1}$ The white matter lesions can be confined to the posterior fossa, as was the case in 3 of 8 patients with PML-IRIS reported in the literature. $^{30}$ The peripheral enhancement of the white matter lesions and perivascular spaces has been related to their infiltration by CD8 + T-cells, sometimes accompanied by macrophages and CD4+ T-cells. ${ }^{1,30}$

If this intense inflammatory response with edema, contrast enhancement, and mass effect can subsequently be mitigated, patients may have an improved outcome. However, not all patients with HIV-associated PML-IRIS demonstrate contrast enhancement of the PML lesions. ${ }^{30}$ Contrast enhancement may be seen in only $56 \%$ of patients. ${ }^{73}$ Indeed, much of the underestimation of PML-IRIS results from the assumption of clinicians that it only occurs when contrast enhancement is seen in PML lesions. In fact, this enhancement may be a late and extreme consequence, with substantial and abnormal inflammatory changes in PML lesions occuring well before gadolinium contrast enhancement. Fortunately, a response can be seen with steroids. ${ }^{1,15,81}$

Yet another tool used to predict patient outcome in HIV-associated PML-IRIS has been diffusion-weighted imaging. A study by Buckle and Castillo ${ }^{74}$ found that in the clinically rapidly progressive patients with PML-IRIS, the ADC values both centrally and totally as well as the JCV titers pre-HAART were the highest, whereas those with lower ADC values were associated with stable lesions or remyelination. Also while the ADC values in the center of the white matter lesion increased only slightly during a 1-month time period on HAART, in those patients whose PML progressed slowly, there was a significant increase in ADC values in the total lesion and central core in those patients with rapid PML progression who had been on HAART for 1 month. ${ }^{74}$ The implication is that because PML is a destructive white matter lesion, increased destruction manifested by increased diffusibility on diffusion-weighted imaging would indicate disease progression and hence poorer patient outcome. ${ }^{74}$

That PML-IRIS can be fulminating and lead to patient death was evident from the case report of Vendrely et $\mathrm{al}^{6}$ of a patient with AIDS with PML started on HAART who subsequently deteriorated neurologically. The patient's MR imaging showed an increase in the number and size of the lesions, all of which enhanced compared with the pre-HAART MR imaging. ${ }^{6}$ Biopsy showed both demyelinating lesions as well as severe inflammation with 


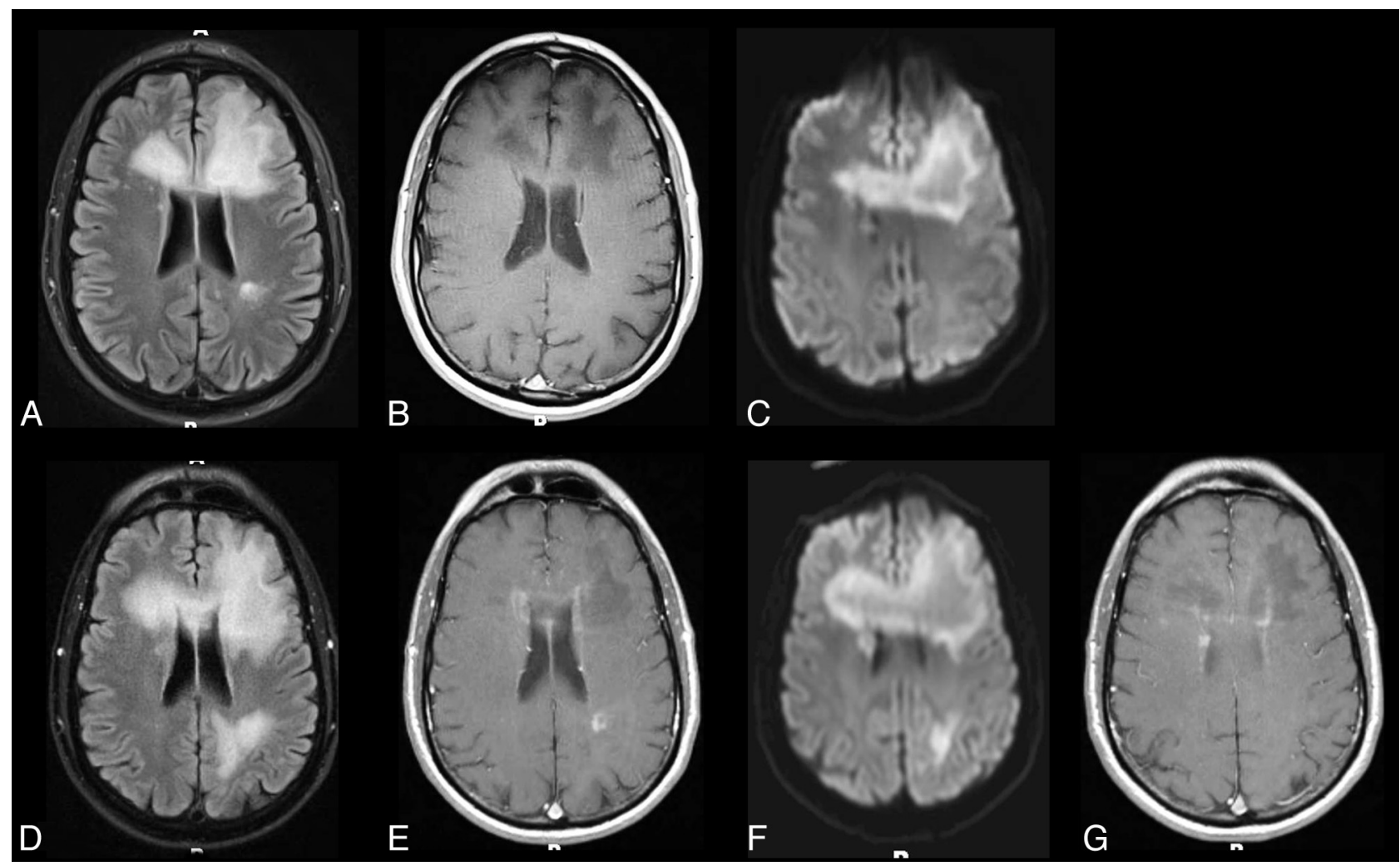

FIG 3. PML-IRIS. HIV-infected patient with personality changes and dysphasia on antiretroviral therapy but noncompliant. Axial FLAIR (A) shows predominantly bifrontal hyperintense white matter lesions with matching low signal on axial postcontrast TIWI $(B)$ without enhancement and with some peripheral restricted diffusion on axial DWI images $(C)$, consistent with PML. Five weeks later following initiation of maraviroc, MR imaging demonstrates progression of the white matter lesions on axial FLAIR (D), the development of some mild patchy enhancement at multiple sites evident on axial gadolinium MR imaging ( $E$ and $G)$, and increasing and new areas of peripheral restricted diffusion on axial DWI ( $F$ ) compatible with IRIS. The patient was placed on steroid therapy to decrease the inflammatory response.

massive T-cell lymphocyte and macrophage infiltration without JCV detection. ${ }^{6}$ Unfortunately, high-dose steroids did not prevent the patient's death. At autopsy, an acute perivenous leukoencephalitis was found, mostly comprised of CD8+ lymphocytes without detectable JC virus in those specific areas. However, areas of abundant JC virus with active PML inflammatory lesions and perivascular and parenchymal infiltration by $\mathrm{T}$ lymphocytes were also found. ${ }^{6}$ While CD8+ lymphocytes were in abundance, CD4+ lymphocytes were absent. The patient's death with PMLIRIS was thought then to be related to a dysregulation of the immune response with an imbalance in the CD8+/CD4+ T-cell ratio. ${ }^{6}$ The marked infiltration of $\mathrm{CD} 8+\mathrm{T}$-cell lymphocytes into the brain parenchyma was not matched by a sufficient enough CD4+ T-cell lymphocyte response. ${ }^{6}$ This led to a perivenous leukoencephalitis as well as an aggravation of the JCV infection. ${ }^{6}$

Virus: PML-IRIS in HIV-Negative Patients on Immunomodulatory Therapies. While not the focus of this article, a brief mention should be made of the fact that in HIV-negative patients such as those with autoimmune diseases treated with immunomodulatory therapies, in organ transplant patients, or in those with hematologic malignancies, PML can occur. ${ }^{47}$ For example, in patients with multiple sclerosis or Crohn disease treated with immunomodulatory medications such as natalizumab (an $\alpha 4 \beta 1$ and $\alpha 4 \beta 7$ integrin inhibitor that binds $\alpha$-integrin molecules on the surface of $\mathrm{T}$ - and B-cells), PML can develop, albeit rarely. ${ }^{47,64,73}$ Since the integrins serve as attachment ligands for the vascular cell adhesion molecules on endothelial cells, natalizumab, by preventing the binding of the integrin onto the vascular cell adhesion molecule, causes a loss in immune surveillance because the T-cells can no longer gain access to the brain. ${ }^{47}$ This complication of PML occurring with biologically immune-modifying therapies ${ }^{82-87}$ has been found to occur during the first 3 years of exposure to natalizumab. ${ }^{83}$ In the first 2 years on this therapy, the incidence has been cited at 1 in $1133 .{ }^{64}$ If subsequently that treatment is terminated and plasmapheresis is performed, the increased trafficking of leukocytes into the CNS can result in PML-IRIS. ${ }^{64,82}$ With plasma exchange, which increases the clearance of natalizumab, clinical symptoms can worsen due to the development of PML-IRIS. ${ }^{83}$

Typical for the IRIS phenomenon, as the patent deteriorates clinically, the PML lesions on MR imaging enlarge and increased gadolinium enhancement can be seen within days to weeks of the plasma exchange. ${ }^{83}$ The PML-IRIS developing in this particular setting is said to be more severe than that observed in the HIV+ patient with PML-IRIS because of the restored immune surveillance. ${ }^{83}$ Neurologic deterioration and even brain herniation and death can occur. ${ }^{83}$ Steroids have been used to dampen this effect of PML-IRIS. Certain other monoclonal antibody therapies that perturb the immune system, such as rituximab (which targets the CD20 cell-surface marker), used in the treatment of lymphoproliferative disease (typically B-cell malignancies), rheumatoid arthritis, and systemic lupus erythematosus, and efalizumab, used 


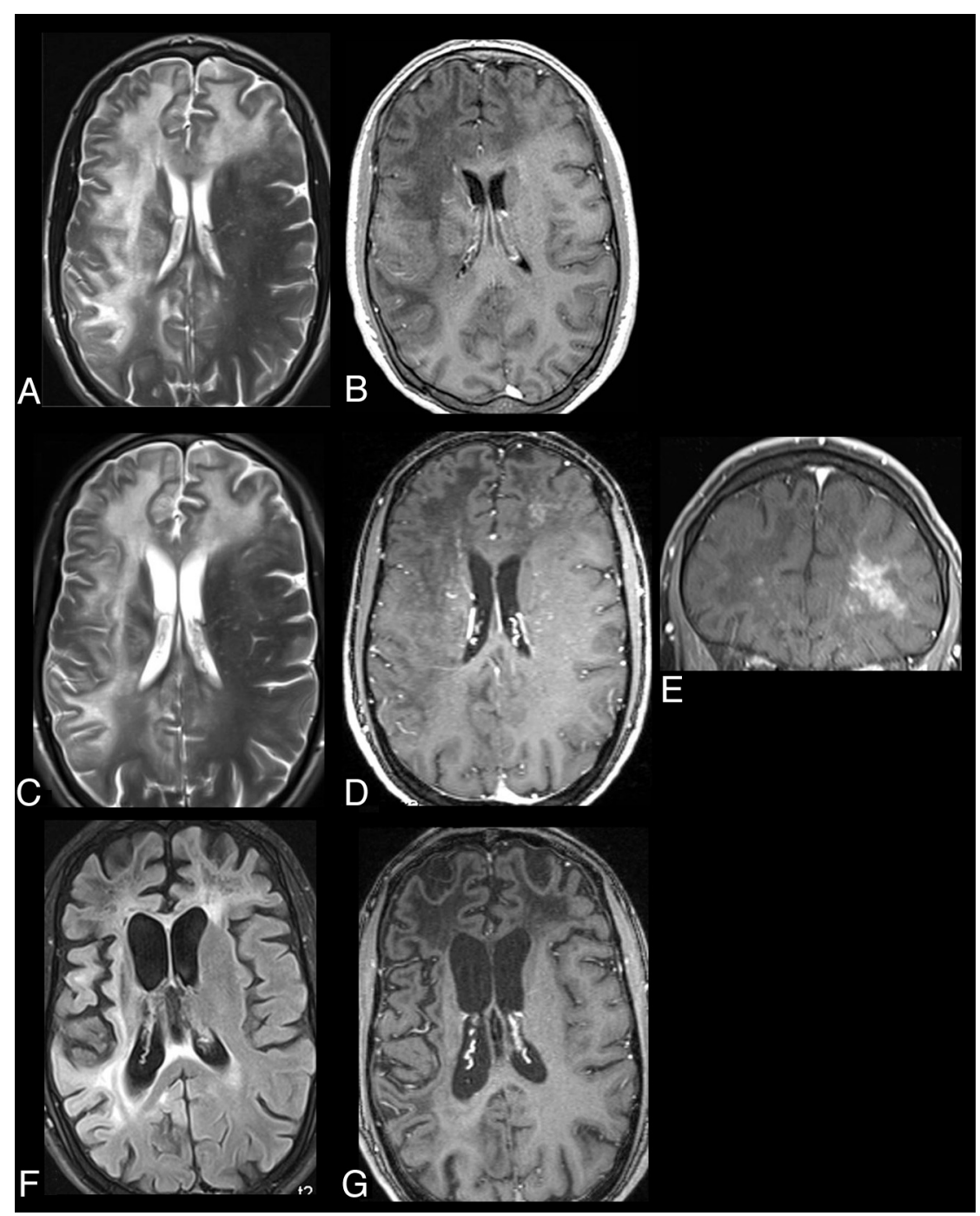

FIG 4. PML-IRIS. AIDS patient with hemiparesis, aphasia, and disorientation. CSF polymerase chain reaction positive for the JC virus (CD4 count, 15 cells $/ \mu$ L). Initial MR imaging pre-HAART with axial T2WI (A) and contrast TIWI (B) showing typical PML lesions with asymmetric white matter hyperintensities in the subcortical and deep white matter in the frontal, parietal, and temporal lobes without mass effect and without enhancement and with matching low signal intensities on the TIWI. Two weeks later after HAART initiation, in addition to the white matter hyperintensities seen on axial FLAIR $(C)$, on contrast MR TIWI with axial $(D)$, and coronal $(E)$ views, perivascular and parenchymal enhancement is now seen bilaterally, greatest in the left frontal lobe. Nine months later, axial FLAIR $(F)$ and contrast TIWI $(G)$ demonstrate resolution of the enhancement, decrease in the white matter hyperintensities, and development of atrophy.

for the treatment of psoriasis (which binds CD11), have also been shown to have an increased risk for PML development and, following cessation, increased risk for PML-IRIS. ${ }^{64}$

\section{Fungus: Cryptococcal Meningitis-IRIS}

Cryptococcus neoformans is an organism that can cause infection frequently seen in association with IRIS. ${ }^{88}$ Cryptococcal-IRIS can be manifested in many different ways-as lymphadenitis, pneumonitis, cryptococcal meningitis, or cryptococcomas-and can result in considerable morbidity and mortality. ${ }^{20,89}$ In CM-IRIS, mortality rates have ranged between $8 \%$ and $30 \% .^{20}$ In fact, according to some investigators, the morbidity and mortality rates have actually increased in CM-IRIS. ${ }^{20}$ For example, in a prospective study of $65 \mathrm{HIV}$-positive patients with proved cryptococcal meningitis on antifungal medication (amphotericin B) who were ART-naïve, IRIS-associated cryptococcal meningitis developed in $17 \%$ ( 11 patients) at a median of 29 days after the initiation of
ART. ${ }^{20}$ While there was a greater immune restoration (as measured by a greater CD4 rise from baseline after 6 months) noted in patients with CM-IRIS as opposed to those with CM without IRIS, there was also a higher mortality rate in the patients with CM-IRIS (4/11 versus 14/54). ${ }^{20}$ There was a trend for those patients developing CM-IRIS to have a higher fungal burden at the end of $\geq 7$ days of initial treatment with amphotericin B. ${ }^{20}$ In another investigation, a prospective study of 101 Ugandans with AIDS without any prior ART exposure who then developed cryptococcal meningitis after ART initiation, IRIS developed in a median time of 8.8 weeks in $45 \%$, with $30 \%$ exhibiting CNS symptoms. ${ }^{90}$ Thirty-six percent of those with CM-IRIS died, compared with $21 \%$ with CM without IRIS. ${ }^{90}$

In a search for serum biomarkers in CM-IRIS that might lead to more advantageous treatment regimens, it was found that the pre-ART serum cryptococcal antigen level was 4 times higher in 


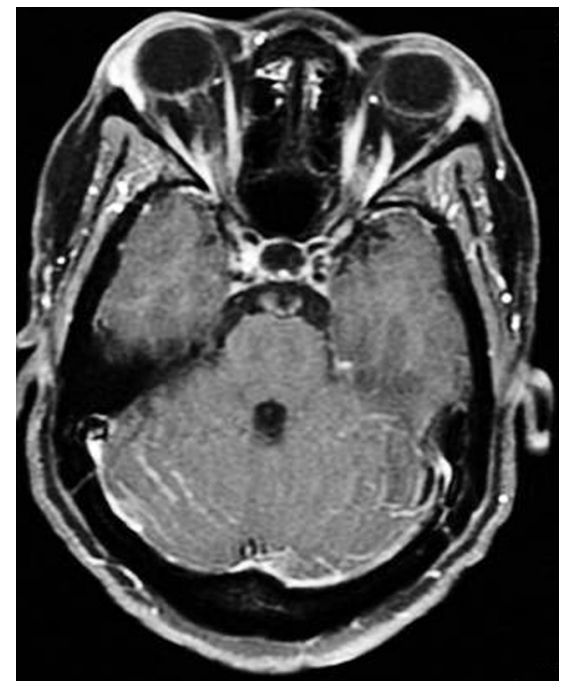

FIG 5. Cryptococcal meningitis-IRIS. Axial TT-weighted image with contrast shows enhancement along the folia of the cerebellum and the meninges in a patient with HIV infection and cryptococcal meningitis who was treated with amphotericin B and then HAART.

those developing CM-IRIS. ${ }^{90}$ Furthermore, a paucity of proinflammatory cytokine responses pre-ART, evidenced by lower tumor necrosis factor $\alpha$, lower vascular endothelial growth factor, lower granulocyte-macrophage colony-stimulating factor, and lower granulocyte colony-stimulating factor combined with heightened Th17 and Th2 responses as measured by higher levels of interleukin 4 and interleukin 17, was predictive of future IRIS. ${ }^{90}$ The authors postulated that these biomarkers could be used to determine when to initiate ART or to guide other interventional therapies. ${ }^{90}$ With patients on ART these authors also found increasing levels of D-dimer and C-reactive protein to be biomarkers pointing to an inflammatory response. ${ }^{90}$

Patients with CM-IRIS can be recognized clinically by the development of headache, fever, malaise, altered mental status, raised intracranial pressure, and cranial nerve palsies in the setting of lymphadenopathy and new pulmonary infiltrates. ${ }^{91}$ Cavitary lung lesions, suppurative mediastinal lymph nodes, and meningismus due to the exaggerated local inflammatory responses from increased reactivity to the cryptococcal antigen and higher cryptococcal antigen titers, a higher fungal burden in the blood, higher opening pressures in the CSF, and sometimes culture-negative CSF are diagnostic clues that may differentiate CM-IRIS from pre-HAART cryptococcal infection. ${ }^{20,25,92}$ Initiating antiretroviral therapy within 1-2 months of the diagnosis of $\mathrm{CM}^{20}$ and CD4 counts below 11 cells $/ \mathrm{mm}^{3}$ as well as higher baseline HIV RNA levels have also been viewed as risk factors for CM-IRIS. ${ }^{25}$

Concerning neuroimaging, certain striking differences have been found in those with CM-IRIS as opposed to HAART-naïve HIV-infected patients with CM. Before the advent of HAART, leptomeningeal enhancement in CM was uncommon in patients with AIDS because those individuals were unable to mount a sufficient inflammatory response. ${ }^{93}$ However, with HAART and CM-IRIS, an intense inflammatory reaction can be seen. Because of a restoring immune system, CT or MR imaging can demonstrate leptomeningeal enhancement (Fig 5), which can be accompanied by a communicating hydrocephalus in CM-IRIS. The findings of linear perivascular enhancement in the sulci and new meningeal or choroid plexus enhancement have been shown to be imaging indicators of CM-IRIS. ${ }^{19,90,94}$ In a case illustrated by Riedel et al, ${ }^{19}$ a cerebellar lesion with high FLAIR signal having mass effect on the fourth ventricle was seen to develop in association with an increase in meningeal enhancement 2 weeks after an HIVinfected patient with CM was treated with antiretroviral therapy.

While distention of the Virchow-Robin spaces manifested as high T2/FLAIR signal, particularly in the basal ganglia, and gelatinous pseudocysts have been imaging features of cryptococcal meningitis in both the pre- and post-HAART era due to the production of a viscous mucoid material by the acidic polysaccharide capsule of the cryptococcal organism, ${ }^{95}$ enhancement of these Virchow-Robin spaces appears characteristic of CM-IRIS as does secondary involvement of the brain parenchyma characterized by areas of high T2/FLAIR signal (Fig 6A), restricted diffusion, and parenchymal enhancement. In a report of $2 \mathrm{HIV}+$ patients with cryptococcal meningitis started on HAART with negative findings on pretreatment MR images, in 1 patient 7 months later, leptomeningeal enhancement was observed and multiple enhancing parenchymal lesions in the cortex compatible with cryptococcomas; whereas in the other patient, focal cortical and subcortical lesions were seen 6 months later. ${ }^{96}$ In a prospective study by Bicanic et al, ${ }^{20}$ contrast CT scans were obtained in 4 of the 65 patients with CM-IRIS. Two of these CT scans showed infarcts, either in the basal ganglia bilaterally or in the unilateral basal ganglia and temporal and parietal lobes. While infarcts can certainly cause restricted diffusion, the gelatinous mucoid material produced by the cryptococcal capsule can also restrict diffusion in the parenchyma. ${ }^{97}$ When there is a sufficient enough inflammatory response induced by IRIS, contrast enhancement can be seen (Fig 6B).

Higher organism burden in the CSF at disease onset in CMIRIS has also been reported to be associated with elevated intracranial pressure. ${ }^{91,92}$ This elevated intracranial pressure is due to the blockage of CSF pathways and arachnoid villi by the production of greater amounts of mucoid material, by the higher number of organisms, and by the greater reactivity to the cryptococcal antigens. ${ }^{91}$ A lumbar drain or ventriculostomy is often necessary to combat the increased mortality (25\%) with elevated intracranial pressure that has been reported. ${ }^{91}$ Because a high opening pressure in patients with CM-IRIS is considered a risk factor for increased mortality, the suggestion has been made to delay for 1 month the institution of HAART in these patients who develop cryptococcal meningitis. ${ }^{91}$ Treatment with amphotericin B and flucytosine for 2 weeks and fluconazole for 8 weeks has been suggested in this setting. ${ }^{91}$

One word of caution should be expressed. While the imaging findings mentioned above can be clues to the diagnosis of CMIRIS, a negative CT or MR imaging finding or one showing only cortical atrophy does not exclude that diagnosis. Several studies have shown significant percentages of patients in whom the MR imaging or CT findings were negative in cryptococcal meningitis. ${ }^{98}$ In fact, a recent article has shown that DTI may be a useful tool in CM because it can detect changes that may be more widespread than anticipated from conventional MR imaging. ${ }^{99}$ Investigating the neuropsychological sequelae in HIV-negative patients 

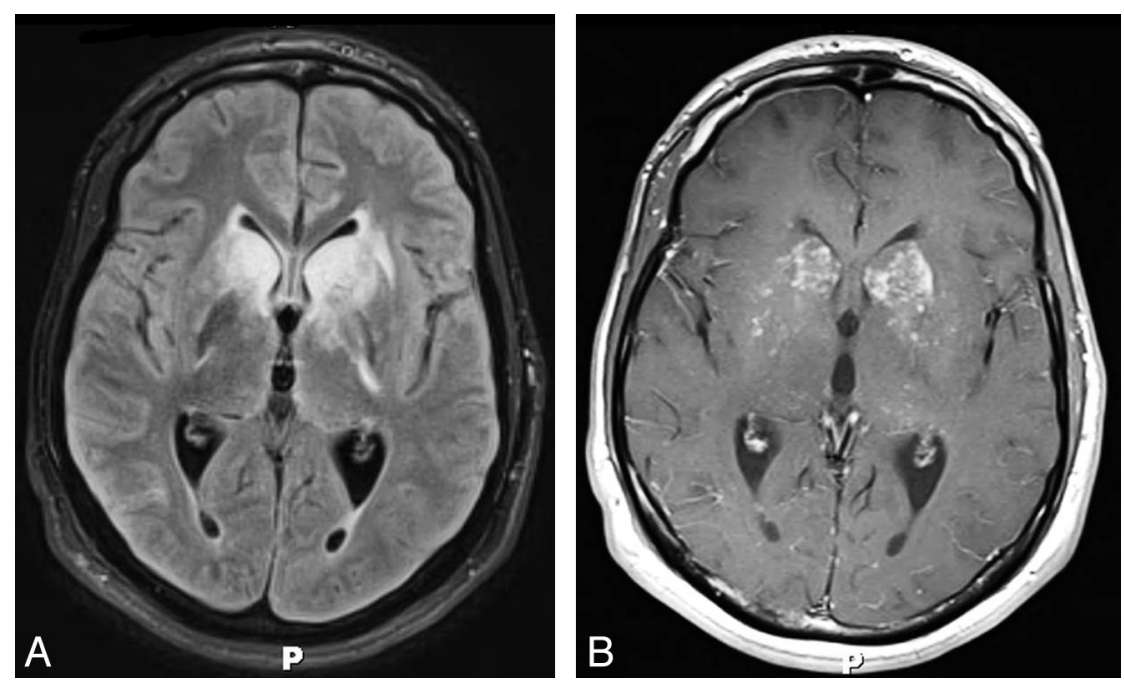

FIG 6. Late cryptococcal meningitis-IRIS. A 29-year-old man with HIV/AIDS and cryptococcal meningitis who was treated successfully. Four months later while on fluconazole and with a CD4 count of 66 cells per microliter and an HIV viral load of 400,000 copies $/ \mathrm{mL}$, he was started on antiretroviral therapy (emtricitabine/tenofovir/efavirenz [Atripla]). Eight months after initiation of the antiretroviral therapy, the patient developed headache, stiff neck, nausea, and vomiting. Axial FLAIR $(A)$ and axial TIWI postcontrast $(B)$ imaging show distention of the VirchowRobin spaces in the basal ganglia with hyperintense signal and enhancement. These images also demonstrate that the inflammatory process has spread into the parenchyma of the basal ganglia, where high FLAIR signal and patchy enhancement are seen. Fungal cultures at this time were negative, and the cryptococcal antigen level was weakly positive. A diagnosis of late IRIS was made, and the patient was started on steroids, to which he responded.

with cryptococcal meningitis and its correlation to microstructural changes in the white matter, these authors found that higher CSF cryptococcal antigen levels were associated with poorer DTI parameters, with increasing ADC values and decreasing fractional anisotropy values and worse cognitive performance. ${ }^{99}$ Their conclusion was that a higher fungal burden correlated with a greater microstructural change in the white matter, which was apparent only by DTI and not by routine MR imaging. ${ }^{99}$ While this study was performed in the HIV-negative population, one can certainly postulate that advanced imaging techniques such as DTI should be very useful in assessing parenchymal damage in CM-IRIS because of the overzealous inflammatory reaction present in some of these patients.

\section{SUMMARY}

While CNS-IRIS is a diagnosis of exclusion, the neuroradiologist can be pivotal in the early recognition of this condition because of often atypical MR imaging and CT findings, which characterize this syndrome, as typified in cryptococcal infection and PML. Contrast enhancement, transient increase in parenchymal abnormalities with high signal on FLAIR, mass effect, and restricted diffusion can be the diagnostic imaging clues to CNS-IRIS. In an $\mathrm{HIV}+$ patient whose severe immunosuppression responds rapidly to HAART while neurologic symptoms worsen, neuroimaging can give credence to the diagnosis of CNS-IRIS, thereby aiding the clinician in the medical management of the patient. Ultimately, if the inflammatory response can be contained as the patient's immune system recovers, the patient's long-term outcome can be improved.

Disclosures: Majda Thurnher—UNRELATED: Royalties: Amirsys. David Clifford—UNRELATED: Consultancy: All <\$10,000 annually: Biogen Idec, Genentech, Millennium, Genzyme, Bristol Myers Squibb, Pfizer, Janssen, Expert Testimony: Biogen Idec, Comments: European Medicines Agency (EMA) discussion of natalizumab, Payment for
Development of Educational Presentations: Millennium, payment for teaching video on exam for PML; Genentech, payment for teaching video on PML diagnosis, Other: Millennium, Independent Adjudication Committee, Genzyme, Data Monitoring Committee, Chair; Genentech, Panel of Experts, Translational Immunology Consultant; Pfizer, Data Safety Monitoring Committee (DSMB).

\section{REFERENCES}

1. Johnson T, Nath A. Neurological complications of immune reconstitution in $\mathrm{HIV}$-infected populations. Ann N Y Acad Sci 2010;1184:106-20

2. Shelburne SA, Visnegarwala F, Darcourt J, et al. Incidence and risk factors for immune reconstitution inflammatory syndrome during highly active antiretroviral therapy. AIDS 2005;19:399-406

3. Shelburne SA III, Hamill R. The immune reconstitution inflammatory syndrome. AIDS Reviews 2003;5:67-79

4. Shelburne SA, Montes M, Hamill RJ. Immune reconstitution inflammatory syndrome: more answers, more questions. J Antimicrob Chemother 2006;57:167-70

5. Muller M, Wandel S, Colebunders $\mathrm{R}$, et al. Immune reconstitution inflammatory syndrome in patients starting antiretroviral therapy for HIV infection: a systematic review and meta-analysis. Lancet Infect Dis 2010;10:251-61

6. Vendrely A, Bienvenu B, Gasnault J, et al. Fulminant inflammatory leukoencephalopathy associated with HAART-induced immune restoration in AIDS-related progressive multifocal leukoencephalopathy. Acta Neuropathol 2005;109:449-55

7. Shelburne SA, III, Hamill RJ, Rodriquez-Barradas MC, et al. Immune reconstitution inflammatory syndrome: emergence of a unique syndrome during highly active antiretroviral therapy. Medicine (Baltimore) 2002;81:213-27

8. Bonham S, Meya DB, Bohjanen PR, et al. Biomarkers of HIV immune reconstitution inflammatory syndrome. Biomark $\mathrm{Med}$ 2008;2:349-61

9. Manabe Y, Campbell JD, Syndor E, et al. Immune reconstitution inflammatory syndrome: risk factors and treatment applications. $J$ Acquir Immune Defic Syndr 2007;46:456-62

10. Grant PM, Komarow L, Andersen J, et al. Risk factor analyses for immune reconstitution inflammatory syndrome in a randomized study of early vs. deferred ART during an opportunistic infection. PLOS ONE 2010;5:e11416

11. Dhasmana DJ, Dheda $\mathrm{K}$, Ravn $\mathrm{P}$, et al. Immune reconstitution inflammatory syndrome in HIV-infected patients receiving antiret- 
roviral therapy: pathogenesis, clinical manifestations and management. Drugs 2008;68:191-208

12. French MA. Disorders of immune reconstitution in patients with HIV infection responding to antiretroviral therapy. Curr HIV/AIDS Rep 2007;4:16-21

13. French MA, Lenzo N, John M, et al. Immune restoration disease after the treatment of immunodeficient HIV-infected patients with highly active antiretroviral therapy. HIV Med 2000;1:107-15

14. French MA. Immune reconstitution inflammatory syndrome: a reappraisal. Clin Infect Dis 2009;48:101-07

15. Tan K, Roda R, Ostrow L, et al. PML-IRIS in patients with HIV infection: clinical manifestations and treatment with steroids. $\mathrm{Neu}$ rology 2009;72:1458-64

16. Berkeley JL, Nath A, Pardo CA. Fatal immune reconstitution inflammatory syndrome with human immunodeficiency virus infection and Candida meningitis: case report and review of the literature. J Neurovirol 2008;14:267-76

17. Navas E, Martin-Davilla P, Moreno L, et al. Paradoxical reactions of tuberculosis in patients with the acquired immunodeficiency syndrome who are treated with highly active antiretroviral therapy. Arch Inn Med 2002;162:97-99

18. Murdoch DM, Venter WDF, Van Rie A, et al. Immune reconstitution inflammatory syndrome (IRIS): review of common infectious manifestations and treatment options. AIDS Res Ther 2007;4:1-10

19. Riedel DJ, Pardo CA, McArthur J, et al. Therapy insight: CNS manifestations of HIV-associated immune reconstitution inflammatory syndrome. Nat Clin Prac Neurol 2006;2:557-65

20. Bicanic T, Meintjes G, Rebe K, et al. Immune reconstitution inflammatory syndrome in HIV-associated cryptococcal meningitis: a prospective study. J Acquir Immune Defic Syndr 2009;51:130-34

21. McCombe JA, Auer RN, Maingat FG, et al. Neurologic immune reconstitution inflammatory syndrome in HIV/AIDS: outcome and epidemiology. Neurology 2009;72:835-41

22. Venkataramana A, Pardo CA, McArthur JC, et al. Immune reconstitution inflammatory syndrome in the CNS of HIV-infected patients. Neurology 2006;67:383-88

23. Gray F, Bazille C, Biassette-Adle $H$, et al. Central nervous system immune reconstitution disease in acquired immunodeficiency syndrome patients receiving highly active antiretroviral treatment. J Neurovirol 2005;11:16-22

24. van der Ven AJ, van Oostenbrugge RJ, Kubat B, et al. Cerebral vasculitis after initiation antiretroviral therapy. AIDS 2002;16:2362-64

25. Murdoch DM, Venter WDF, Feldman C, et al. Incidence and risk factors for the immune reconstitution inflammatory syndrome in HIV patients in South Africa: a prospective study. AIDS 2008;22:601-10

26. Robertson J, Meier M, Wall J, et al. Immune reconstitution syndrome in HIV: validating a case definition and identifying clinical predictors in persons initiating antiretroviral therapy. Clin Infec Dis 2006;42:1639-46

27. Stoll $M$, Schmidt RE. Immune restoration inflammatory syndromes: apparently paradoxical clinical events after the initiation of HAART. Curr HIV/AIDS Rep 2004;1:122-27

28. Singer EJ, Sueiras-Valdes M, Commins D, et al. Neurologic presentations of AIDS. Neurol Clin 2010;28:253-75

29. Sexton DJ, Pien BC, et al. Immune reconstitution inflammatory syndrome. UpToDate. Available at http://www.uptodate.com. Accessed January 31, 2012

30. McCarthy M, Nath A. Neurologic consequences of the immune reconstitution inflammatory syndrome (IRIS). Curr Neurol Neurosci Rep 2010;10:467-75

31. McArthur JC, Steiner J, Sacktor N, et al. Human immunodeficiency virus-associated neurocognitive disorders: mind the gap. Ann Neurol 2010;67:699-714

32. DeSimone JA, Pomerantz RJ, Babinchak TJ. Inflammatory reactions in HIV-1-infected persons after initiation of highly active antiretroviral therapy. Ann Intern Med 2000;133:447-54

33. French MA, Mallal SA, Dawkins RL. Zidovudine-induced restoration of cell-mediated immunity to mycobacteria in immunodeficient HIV-infected patients. AIDS 1992;6:1293-97

34. Ohta $\mathrm{K}$, Kishida S. Immune reconstitution inflammatory syndrome in the central nervous system. Brain Nerve 2007;59:1355-62

35. Rushing EJ, Liappis A, Smirniotopoulos JD, et al. Immune reconstitution inflammatory syndrome of the brain: case illustrations of a challenging entity. J Neuropathol 2008;67:819-27

36. Nath A, Geiger J. Neurobiological aspects of human immunodefi- ciency virus infection: neurotoxic mechanisms. Prog Neurobiol 1998;54:19-33

37. Navdeesh S, McCutchan JA. Unmasking of PML by HAART: unusual clinical features and the role of IRIS. I Neuroimmunol 2010;219:100-04

38. Teo EC, Azwra A, Jones R, et al. Guillain-Barre syndrome following immune reconstitution after antiretroviral therapy for primary HIV infection. J HIV Ther 2007;12:62-63

39. Anthony IC, Bell JE. Neuropathological findings associated with long-term HAART. In: Paul RH, Sacktor NC, Valcour V, et al, eds. HIV and the Brain: New Challenges in the Modern Era. New York: Humana Press; 2009:29-47

40. Bazille GF, Biassette MH, Moulignier A, et al. Central nervous system immune reconstitution disease in acquired immunodeficiency syndrome patients receiving highly active antiretroviral treatment. J Neurovirol 2005;3:16-22

41. Ratnam I, Chiu C, Kandala NB, et al. Incidence and risk factors for immune reconstitution inflammatory syndrome in an ethnically diverse HIV type 1-infected cohort. Clin Infect Dis 2006;42:418-27

42. Huruy K, Andargachew M, Getahun M, et al. Immune reconstitution inflammatory syndrome among HIV/AIDS patients during highly active antiretroviral therapy in Addis Ababa, Ethiopia. J Infect Dis 2008;61:205-09

43. Gray F, Chrétien F, Vallat-Decouvelaere AV, et al. The changing pattern of HIV neuropathology in the HAART era. J Neuropathol Exp Neurol 2003;62:429-40

44. Price P, Morahan G, Huang D, et al. Polymorphisms in cytokine genes define subpopulations of HIV-1 patients who experienced immune restoration diseases. AIDS 2002;16:2043-47

45. Wang ME, Castillo ME, Silvia M, et al. Immune reconstitution inflammatory syndrome in human immunodeficiency virus-infected children in Peru. Pediatr Infect Dis J 2009;28:900-03

46. Kilborn T, Zampoli M. Immune reconstitution inflammatory syndrome after initiating highly active antiretroviral therapy in HIVinfected children. Pediatr Radiol 2009;39:569-74

47. Major E. Progressive multifocal leukoencephalopathy in patients on immunomodulatory therapies. Annu Rev Med 2010;61:35-47

48. Hoffman C, Horst HA, Albrecht H, et al. Progressive multifocal leukoencephalopathy with unusual inflammatory response during antiretroviral treatment. J Neurol Neurosurg Psychiatry 2003;74:1142-44

49. Safdar A, Ruocki RJ, Horvath JA, et al. Fatal immune restoration disease in human immunodeficiency virus type 1-infected patients with progressive multifocal leukoencephalopathy: impact of antiretroviral therapy-associated immune reconstitution. Clin Infect Dis 2002;35:1250-57

50. Tantisiriwat W, Tebas P, Clifford DB, et al. Progressive multifoca leukoencephalopathy in patients with AIDS receiving highly active antiretroviral therapy. Clin Infect Dis 1998;28:1152-54

51. Cinque P, Pierotti C, Vigano MG, et al. The good and evil of HAART in HIV-related progressive multifocal leukoencephalopathy. $\mathrm{JNeu}$ rovirol 2001;7:358-63

52. Cinque P, Bossolasco S, Brambilla AM, et al. The effect of highly active antiretroviral therapy-induced immune reconstitution on development and outcome of progressive multifocal leukoencephalopathy: study of $\mathbf{4 3}$ cases with review of the literature. J Neurovirol 2003;9:73-80

53. Sidhu N, McCutchan JA. Unmasking of PML by HAART: unusua clinical features and the role of IRIS. J Neuroimmunol 2010;219. 100-04

54. D'Amico R, Sarkar S, Yusuff J, et al. Immune reconstitution after potent antiretroviral therapy in AIDS patients with progressive multifocal leukoencephalopathy. Scand J Infect Dis 2007;39:347-50

55. Nuttall JJ, Wilmshurst JM, Ndondo AP, et al. Progressive multifoca leukoencephalopathy after initiation of highly active antiretrovira therapy in a child with advanced human immunodeficiency virus infection: a case of immune reconstitution inflammatory syndrome. Pediatr Infect Dis 2004;23:683-85

56. Miller RF, Issacson PG, Hall-Craggs M, et al. Cerebral CD8 lymphocytosis in HIV-1 infected patients with immune restoration induced by HAART. Acta Neuropathol 2004;108:17-23

57. Vidal JE, Penalva de Oliveira AC, Fink MC, et al. Aids-related progressive multifocal leukoencephalopathy: a retrospective study in a referral center in Sao Paulo, Brazil. Rev Inst Med Trop Sao Paulo 2008;50:209-12

58. Berger JR, Levy RM Flomenhoft D, et al. Predictive factors for pro- 
longed survival in acquired immunodeficiency syndrome-associated progressive multifocal leukoencephalopathy. Ann Neurol $1998 ; 44: 341-49$

59. Cedeno-Laurent F, Penalva de Oliveira AC, Vidal JE, et al. Human polyomavirus-associated cerebral disorders in the post-HAART era. Patholog Res Int 2011;22:562427

60. Wyen C, Hoffmann C, Schmeisser N, et al. Progressive multifocal leukoencephalopathy in patients on highly active antiretroviral therapy: survival and risk factors of death. J Acquir Immune Defic Syndr 2004;37:1263-68

61. Marra CM, Rajicic N, Barker DE, et al, and the Adult AIDS Clinical Trials Group 363 Team. A pilot study of cidofovir for progressive multifocal leukoencephalopathy (PML) in AIDS. AIDS 2002;13:1791-97

62. Post MJ, Yiannoutsos C. Simpson D, et al. Progressive multifocal leukoencephalopathy in AIDS: are there any MR findings useful to patient management and predictive of patient survival? AJNR Am J Neuroradiol 1999;20:1896-906

63. Berger JR, Kaszovitz B, Post MJ, et al. Progressive multifocal leukoencephalopathy associated with human immunodeficiency virus infection; a review of the literature with a report of sixteen cases. Ann Intern Med 1987;107:78-87

64. Berger JR Houff SA, Major EO. Monoclonal antibodies and progressive multifocal leukoencephalopathy. MAbs 2009;1:583-89

65. Clifford DB, Yiannoutsos C, Glicksman M, et al. HAART improves prognosis in HIV-associated progressive multifocal leukoencephalopathy. Neurology 1999;52:623-25

66. Gasnault J, Taoufik Y, Goujard C, et al. Prolonged survival without neurological improvement in patients with AIDS-related progressive multifocal leukoencephalopathy on potent combined antiretroviral therapy. J Neurovirol 1999;5:421-29

67. Bereenguer J, Miralles P, Arrizabalaga J, et al. Clinical course and prognostic factors of progressive multifocal leukoencephalopathy in patients treated with highly active antiretroviral therapy. Clin Infect Dis 2003;36:1047-52

68. Katz-Brull R, Lenkinski RE, Du Pasquier RA, et al. Elevation of myoinositol is associated with disease containment in progressive multifocal leukoencephalopathy. Neurology 2004;63:897-900

69. Cuvinciuc V, Martin-Blonde G, Marchou B, et al. Proton MR spectroscopy of progressive multifocal leukoencephalopathy-immune reconstitution inflammatory syndrome. AJNR Am J Neuroradiol 2010;31:E69-70

70. Chang L, Ernst T, Tornatore C, et al. Metabolite abnormalities in progressive multifocal leukoencephalopathy by proton magnetic resonance spectroscopy. Neurology 1997;48:836-45

71. Thurnher MM, Post MJ, Rieger A, et al. Initial and follow-up MR imaging findings in AIDS-related progressive multifocal leukoencephalopathy treated with highly active antiretroviral therapy. AJNR Am J Neuroradiol 2001;22:977-84

72. Usiskin SI, Bainbridge A, Miller RF, et al. Progressive multifocal leukoencephalopathy: serial high-b-value diffusion-weighted MR imaging and apparent diffusion coefficient measurements to assess response to highly active antiretroviral therapy. AJNR Am J Neuroradiol 2007;28:285-86

73. Bag AK, Cure JK, R, Chapman PR, et al. JC virus infection of the brain. AJNR Am J Neuroradiol 2010;31:1564-76

74. Buckle C, Castillo M. Use of diffusion-weighted imaging to evaluate the initial response of progressive multifocal leukoencephalopathy to highly active antiretroviral therapy: early experience. AJNR Am J Neuroradiol 2010;31:1031-35

75. Gheuens S, Bord E, Kesari S, et al. Role of CD4+ and CD8+ T-cell responses against $\mathrm{JC}$ virus in the outcome of patients with progressive multifocal leukoencephalopathy (PML) and PML-IRIS. J Virol 2011;85:7256-63

76. Collazos J, Mayo J, Martinez E, et al. Contrast enhancing PML as an immune reconstitution event in AIDS patients. AIDS 1999;13:1426-28

77. Koralnik IJ. Progressive multifocal leukoencephalopathy revisited: has the disease outgrown its name? Ann Neurol 2006;60:162-73

78. Whiteman ML, Post MJ, Berger JR, et al. Progressive multifocal leukoencephalopathy in $47 \mathrm{HIV}$-seropositive patients: neuroimaging with clinical and pathologic correlation. Radiology 1993;187:233-40
79. Giancola ML, Rizzi EB, Lorenzini P, et al. Progressive multifocal leukoencephalopathy in HIV-infected patients in the era of HAART: radiological features at diagnosis and follow-up and correlation with clinical variables. AIDS 2008;2:155-62

80. Kotecha N, George MJ, Smith TW, et al. Enhancing progressive multifocal leukoencephalopathy: an indicator of improved immune status? Am J Med 1998;105:541-43

81. Berger JR. Steroids for PML-IRIS: a double-edged sword? Neurology 2009;72:1454-55

82. Weissert R. Progressive multifocal leukoencephalopathy. J Neuroimmunol 2011;231:73-77

83. Clifford DB, DeLuca A, Simpson DM, et al. Natalizumab-associated progressive multifocal leukoencephalopathy in patients with multiple sclerosis: lessons from 28 cases. Neurology 2010;9:438-46

84. Ransohoff RM. "Thinking without thinking” about natalizumab and PML. J Neurol Sci 2007;259:50-52

85. Yousry TA, Major EO, Ryschkewitsch C, et al. Evaluation of patients treated with natalizumab for progressive multifocal leukoencephalopathy. N Engl J Med 2006;354:924-33

86. Kleinschmidt-DeMasters BK, Tyler KL. Progressive multifocal leukoencephalopathy complicating treatment with natalizumab and interferon beta-1a for multiple sclerosis. $N$ Engl J Med 2005;353:369-74

87. Berger JR, Koralnik IJ. Progressive multifocal leukoencephalopathy and natalizumab-unforeseen consequences. $N$ Engl J Med 2005;353:414-16

88. Tahir M, Sharma SK, Sinha S, et al. Immune reconstitution inflammatory syndrome in a patient with cryptococcal lymphadenitis as the first presentation of acquired immunodeficiency syndrome. $J$ Postgrad Med 2007;53:250-52

89. Haddow LJ, Colebunders R, Meintjes G, et al. Cryptococcal immune reconstitution inflammatory syndrome in HIV-1 infected individuals: literature review and proposed clinical case definition. Lancet Infect Dis 2010;10:781-802

90. Boulware DR, Meya DB, Bergemann TL, et al. Clinical features and serum biomarkers in HIV immune reconstitution inflammatory syndrome after cryptococcal meningitis: a prospective cohort study. PloS Med 2010;7:e1000384

91. Bicanic T, Harrison TS. Cryptococcal meningitis. Br Med Bull 2004;72:99-118

92. Sungkanuparph S, Filler SG, Chetchotisakd P, et al. Cryptococcal immune reconstitution inflammatory syndrome after antiretroviral therapy in AIDS patients with cryptococcal meningitis: a prospective multicenter study. Clin Infec Dis 2009;49:-931-34

93. Matthews VP, Alo PL, Glass JD, et al. AIDS-related CNS cryptococcosis: radiologic-pathologic correlation. AJNR Am J Neuroradiol 1992;13:1477-86

94. King MD, Perlino CA, Cinnamon J, et al. Paradoxical recurren meningitis following therapy of cryptococcal meningitis: an immune reconstitution syndrome after initiation of highly active antiretroviral therapy. Int J STD AIDS 2002;13:724-26

95. Saigal G, Post MJ, Lolayekar S, et al. Unusual presentation of central nervous system cryptococcal infection in an immunocompetent patient. AJNR Am J Neuroradiol 2005;26:2522-26

96. Cattelan AM, Trevenzoli M, Sasset L, et al. Multiple cerebral cryptococcomas associated with immune reconstitution in HIV-infection. AIDS 2004;18:49-51

97. Saigal G, Post MJ, Kirwan R., et al. CNS cryptococcal infection: cor relation of restricted diffusion and leptomeningeal enhancement with CSF cryptococcal antigen levels before and after medical therapy. In: Proceedings of the 44th Annual Meeting of the American Society of Neuroradiology, San Diego, California. May 6-12, 2006

98. Lee YC, Wang JT, Sun HY, et al. Comparisons of clinical features and mortality of cryptococcal meningitis between patients with and without human immunodeficiency virus infection. J Microbiol Immunol Infect 2011;44:338-35

99. Lu C-H, Chen H-L, Chang N-W, et al. Assessing the chronic neuropsychologic sequelae of human immunodeficiency virus-negative cryptococcal meningitis by using diffusion tensor imaging. AJNR Am J Neuroradiol 2011;32:1333-39 